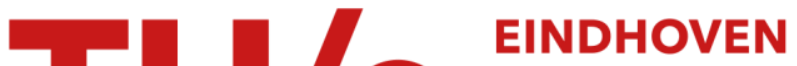

\section{Molecular aspects of the formation of shish-kebab in isotactic polypropylene}

\section{Citation for published version (APA):}

Balzano, L., Ma, Z., Cavallo, D., van Erp, T. B., Fernandez-Ballester, L., \& Peters, G. W. M. (2016). Molecular aspects of the formation of shish-kebab in isotactic polypropylene. Macromolecules, 49(10), 3799-3809. https://doi.org/10.1021/acs.macromol.6b00428

\section{Document license:}

TAVERNE

DOI:

10.1021/acs.macromol.6b00428

Document status and date:

Published: 09/05/2016

\section{Document Version:}

Publisher's PDF, also known as Version of Record (includes final page, issue and volume numbers)

\section{Please check the document version of this publication:}

- A submitted manuscript is the version of the article upon submission and before peer-review. There can be important differences between the submitted version and the official published version of record. People interested in the research are advised to contact the author for the final version of the publication, or visit the $\mathrm{DOI}$ to the publisher's website.

- The final author version and the galley proof are versions of the publication after peer review.

- The final published version features the final layout of the paper including the volume, issue and page numbers.

Link to publication

\section{General rights}

Copyright and moral rights for the publications made accessible in the public portal are retained by the authors and/or other copyright owners and it is a condition of accessing publications that users recognise and abide by the legal requirements associated with these rights.

- Users may download and print one copy of any publication from the public portal for the purpose of private study or research.

- You may not further distribute the material or use it for any profit-making activity or commercial gain

- You may freely distribute the URL identifying the publication in the public portal.

If the publication is distributed under the terms of Article 25fa of the Dutch Copyright Act, indicated by the "Taverne" license above, please follow below link for the End User Agreement:

www.tue.nl/taverne

Take down policy

If you believe that this document breaches copyright please contact us at:

openaccess@tue.nl

providing details and we will investigate your claim. 


\title{
Molecular Aspects of the Formation of Shish-Kebab in Isotactic Polypropylene
}

\author{
Luigi Balzano, ${ }^{\ddagger} \S$ Zhe Ma, ${ }^{*}{ }^{\dagger}, \|$ Dario Cavallo, ${ }^{\ddagger}$ Tim B. van Erp, ${ }^{\ddagger}$ Lucia Fernandez-Ballester, ${ }^{\perp}$ \\ and Gerrit W. M. Peters $*$,,$\S$ \\ ${ }^{\dagger}$ Tianjin Key Laboratory of Composite and Functional Materials, and School of Materials Science and Engineering, Tianjin \\ University, Tianjin 300072, China \\ ${ }^{*}$ Department of Mechanical Engineering, Eindhoven University of Technology, P.O. Box 513, 5600 MB Eindhoven, The Netherlands \\ ${ }^{\S}$ Dutch Polymer Institute (DPI), P.O. Box 902, 5600 AX Eindhoven, The Netherlands \\ "Collaborative Innovation Center of Chemical Science and Engineering (Tianjin), Tianjin 300072, China \\ ${ }^{\perp}$ DUBBLE beamline, European Synchrotron Radiation Facility (ESRF), BP 220, F-38043, Grenoble, Cedex, France
}

ABSTRACT: To elucidate the mechanism of formation of shish-kebab, flow-induced crystallization of isotactic polypropylene is investigated using model slit-flow experiments in combination with in situ small-angle X-ray scattering (SAXS) and wide-angle X-ray diffraction (WAXD). The results, consistent with nucleation and growth theory, show that a brief but intense pulse of shear is sufficient to trigger structure formation, even at temperatures as high as $165{ }^{\circ} \mathrm{C}$, i.e., close to the nominal melting point of the material, $163{ }^{\circ} \mathrm{C}$. Working at such a high temperature allows for a clear separation of the nucleation step, taking place during flow, and the growth step, taking place after flow ceases. A small degree of crystallinity stabilizes the fibrillar crystallization precursors, formed in the early stages, and prevents them from dissolving

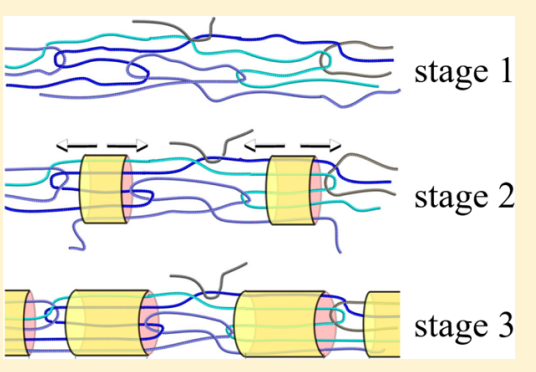
by allowing the molecules involved to retain a stretched conformation. The stretched molecular configuration is essential for further crystallization in this high temperature range. A kinetic analysis indicates that crystallization within the fibrillar shish is based on the unidirectional propagation of a growth front, whereas in a later stage when kebab crystallizes, a bidimensional growth front is observed and the space is rapidly filled until impingement occurs. The lateral dimensions of shish-kebab (as obtained from SAXS analysis) indicate that shish occupy only a small fraction ( $7 \%)$ of the volume. Moreover, the lateral growth rate of the kebabs is an order of magnitude larger than expected from quiescent spherulitical growth.

\section{INTRODUCTION}

The processability of polymers provides industry with the freedom of designing parts that have complex shapes and are light weight, insulating, tough, durable, etc. In many production processes, polymers are shaped into final products from the molten state via nonisothermal pressure-driven flows. It is wellknown that the processing parameters influence the final properties, especially in the case of semicrystalline polymers where the crystallization behavior (kinetics, phases, and morphology) is drastically affected by external conditions. ${ }^{1-4}$ The relation between processing variables (cooling rate, stress, pressure, and time) and crystallization behavior depends in an intricate way on a number of molecular features such as chemical nature, molecular weight distribution, microstructure, and topology of the molecular chains. Often, in the open literature, these relations are only qualitative and therefore too generic to contribute to the development of new products circumventing strategies involving "trial and error". For instance, it is known that a small amount of high molecular weight molecules can enhance kinetics and facilitate the formation of oriented morphologies when crystallization takes place under the influence of stress. ${ }^{5-8}$ However, quantitative relations (predictive models) describing this phenomenon are rare. Only recently some papers were published where all processing conditions, for realistic ranges (high pressures, high cooling rates, high shear rates), were taken into account. ${ }^{9-11}$ The limited knowledge available to-date originates from the complexity of the material-processing-morphology relation that often makes the interpretation of experiment results difficult. To shine some light, research focuses on model systems and well-defined experiments where the link between processing variables and the features of crystallization can be clearly identified. ${ }^{12-19}$

The present work deals with the relation between flow and crystallization kinetics in the regime of high flow stress, where shish-kebabs are the building blocks of the final morphology. In these conditions, during flow, because of the large deformations (orientation and stretch) from the random coil conformation, molecules in the melt can occasionally experience an unusually close lateral packing and form dense fibrillar aggregates. ${ }^{20,21}$ These aggregates (bundles of molecules) are the precursors of shish-kebab, and they are likely to have more structure than

Received: February 28, 2016

Revised: $\quad$ May 4, 2016

Published: May 9, 2016 
transient density fluctuations of mere "rheological" origin. ${ }^{22}$ In fact, literature shows that the lifetime of these precursors is much longer than the rheological time scales even when the temperature is above the melting point of the material. ${ }^{23-27}$ These observations indicate the existence of a mechanism that can stabilize precursors. Several authors have speculated on the nature of this stabilizing mechanism. Among others, Cavallo et al. $^{25}$ suggested that point-like crystal nuclei can develop within thread-like precursors and enhance their stability beyond rheological terms. However, a solid validation of this hypothesis, for instance Bragg diffraction peaks from the nuclei, is still lacking.

The evolution of fibrillar precursors is very sensitive for external conditions. At sufficiently large undercooling, obtained by lowering temperature ${ }^{28}$ or by increasing pressure, ${ }^{29}$ they rapidly crystallize, following a pathway dictated by the highly anisotropic molecular conformation, and transform into shish.

The final morphology of shish generated from isotactic polypropylene (iPP) at very high shear rates was investigated already in the early 1980s by Schultz et al. and Petermann et al. using a combination of TEM and SAXS. ${ }^{30,31}$ They demonstrated that shish are semicrystalline aggregates where high density (crystalline) domains alternate with low density (disordered) domains in the longitudinal direction and that this density modulation is characterized by a periodicity of $\sim 10$ $\mathrm{nm}$. The origin of the density modulation is attributed to the initially defected nature of shish in combination with the collective alignment of molecules along the shish backbone. ${ }^{20,32}$ In this situation, certain defects (kinks, jogs) are very mobile in the longitudinal direction and, driven by free energy minimization, migrate out of crystals in order to cluster and give rise to domains with liquid-like density. As pointed out by Petermann et al., ${ }^{31}$ this structure formation pathway, called "defect clustering", is consistent both with a nucleation and growth mechanism and with spinodal decomposition. The actual crystallization pathway can be inferred by analyzing the development of the SAXS signal as a function of time.

The semicrystalline nature of shishes was investigated also by Grubb et al. in ultrahigh molecular weight polyethylene fibers by looking at contraction and extension of specimens during thermal cycles. ${ }^{33,34}$ However, the model proposed is not entirely equivalent to that of Schultz et al. and of Petermann et al. as Grubb et al. describe the low-density regions as randomly (rather than periodically) distributed along the longitudinal direction (with a most probable spacing lying between 25 and $55 \mathrm{~nm})$.

The differences in the models proposed by Schultz et al. and Petermann et al. and that by Grubb et al. may arise from the different polymeric systems that have been investigated, i.e., from differences in the molecular characteristics (chemical nature, molecular weight distribution, and so on) and in the sample preparation conditions. The objective of this work is to investigate in detail the evolution of the formation of shish and the successive growth of kebab in polypropylene, from the formation of precursors to the development of a morphology with high- and low-density (crystalline and amorphous) domains.

\section{EXPERIMENTAL SECTION}

Material. The polymer studied in this work is an isotactic polypropylene homopolymer Borealis HD120M0, kindly supplied by Borealis $\mathrm{GmbH}$, which has a weight-average molecular weight $M_{\mathrm{w}}$ of $365 \mathrm{~kg} / \mathrm{mol}$, molecular weight distribution $M_{\mathrm{w}} / M_{\mathrm{n}}$ of 5.2 , and tacticity of $97.5 \% \mathrm{mmmm}$ (from FTIR). ${ }^{35}$ The nominal melting point measured by differential scanning calorimeter at a heating rate of 10 ${ }^{\circ} \mathrm{C} / \mathrm{min}$ is $163{ }^{\circ} \mathrm{C}$. In the distribution of molecular weight, chains of various lengths are contributing not equally. The chains with high molecular weight play the central role in flow-induced crystallization because the long chains are much easier to be oriented and even stretched by flow. The disengagement time $\left(\tau_{\mathrm{D}}\right)$, related to the high molecular weight tail, was determined from linear viscoelastic measurements ${ }^{36}$ to be $25 \mathrm{~s}$, and the corresponding stretch relaxation time $\left(\tau_{\mathrm{s}}\right)$ is $0.12 \mathrm{~s}$ at $165{ }^{\circ} \mathrm{C} .{ }^{37}$

Methods. In Situ X-ray Characterization. Small-angle X-ray scattering (SAXS) and wide-angle X-ray diffraction (WAXD) were performed during the same session, although not simultaneously, at the beamline BM26B of the European Synchrotron Radiation Facility (Grenoble, France), ${ }^{38}$ where the wavelength of X-ray was $\lambda=1.0 \AA$. For SAXS, a gas-filled detector with $512 \times 512$ pixels of $260 \mu \mathrm{m} \times 260$ $\mu \mathrm{m}$ was used to collect images with an exposure time of $3 \mathrm{~s}$ at $6.4 \mathrm{~m}$ from the sample. For WAXD, a CCD detector (Photonic Science, UK) with $2000 \times 1336$ pixels of $44 \mu \mathrm{m} \times 44 \mu \mathrm{m}$ was placed at $0.18 \mathrm{~m}$ and operated with an exposure time of $5 \mathrm{~s}$. SAXS and WAXD images were processed with the software Fit $2 \mathrm{D}^{39}$ to obtain plots of intensity versus the norm of the scattering vector $s=2 \sin (\theta) / \lambda$, where $2 \theta$ is the scattering angle.

Flow Cell. Flow-induced crystallization was investigated performing short-term shear in a slit-flow cell mounted on a modified multipass rheometer (MPR). In this cell, specimens are confined in a rectangular slit (width $a=6 \mathrm{~mm}$, thickness $b=1.5 \mathrm{~mm}$, and length $L=120 \mathrm{~mm}$ ) fed by cylindrical reservoirs (diameter $12 \mathrm{~mm}$ ) (see Figure 1). These

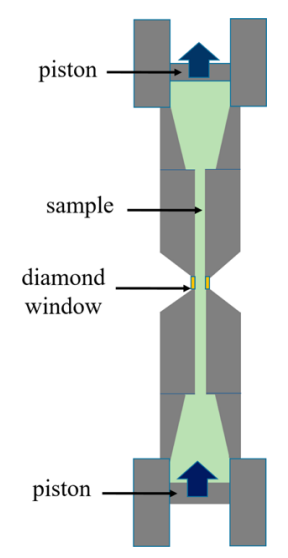

Figure 1. Schematic of the flow device.

reservoirs, in line with the slit, are closed with hydraulically activated pistons. The top and bottom reservoirs are equipped with heating jackets, the middle part of the flow cell has internal channels for circulating heating oil, and thermocouples installed for a temperature control. Flow in the slit is obtained by moving the two pistons simultaneously upward or downward. ${ }^{40}$ The slit is equipped with pressure transducers at the two ends of the slit to measure pressure difference. This can be used to determine the rheological behavior of the polymer. A pair of diamond windows in the middle of slit makes the sample accessible for scattering experiments. When performing experiments, the maximum displacement of the pistons is chosen such that material from the reservoir, which has experienced a complex entrance flow history, does not arrive at the observation windows. For all the experiments discussed in this work, the displacement of the piston is $3 \mathrm{~mm}$. To obtain an optimal filling of the slit and rule out wall slippage, prior to the actual experiment, the specimen is pressurized up to 100 bar by moving the two pistons toward each other.

The control system allows for setting the speed and the displacement of the pistons making this instrument strain controlled. When pistons move, shear rate $\dot{\gamma}$ and stress $\sigma$ increase from the centerline (where $\dot{\gamma}=\sigma=0$ ) until the wall (where $\dot{\gamma}=\dot{\gamma}_{\mathrm{w}}$ and $\sigma=\sigma_{\mathrm{w}}$ ). 
We assume fully developed (stationary) and incompressible laminar flow and shear thinning behavior according to a power law:

$$
\eta(\dot{\gamma})=k \dot{\gamma}^{n-1}
$$

with two parameters $k$ and $n$ (for the iPP studied, $k=9034 \mathrm{~Pa} \cdot \mathrm{s}$ and $n$ $=0.43$ which are obtained by fitting the results of frequency sweep linear rheological measurements at $165^{\circ} \mathrm{C}$ ). With this relation the flow quantities can be calculated analytically as a function of the distance from the centerline $y$. The velocity profile $v(y)$ is linked to the pressure drop $\Delta P / L$, geometrical parameters of the slit ( $L$ and $b)$, and rheological parameters of the material according to ${ }^{36}$

$$
v(y)=\frac{n}{n+1}\left(\frac{\Delta P}{k L}\right)^{1 / n}\left[\left(\frac{1}{2} b\right)^{(n+1) / n}-y^{(n+1) / n}\right]
$$

with $y \in[-b / 2, b / 2]$, while the shear rate is given by

$$
\dot{\gamma}(y)=\frac{\mathrm{d} v}{\mathrm{~d} y}=-\left(\frac{\Delta P}{k L}\right)^{1 / n} y^{1 / n}
$$

and the stress by

$$
\sigma(y)=\eta(\dot{\gamma}) \times \dot{\gamma}=k \dot{\gamma}^{n}=\left(\frac{\Delta P}{L}\right) y
$$

This shows a well-known feature of slit flow; the stress increases linearly from the centerline $(\sigma=0)$ to the wall $\left(\sigma_{\mathrm{w}}=(\Delta P / L) b / 2\right)$.

In eqs $2-4$, the pressure drop $\Delta P$ is the variable that is measured during flow.

For a chosen flow rate $Q$ the pressure difference $\Delta P$ is calculated from

$$
Q=\frac{2 n}{2 n+1} a\left(\frac{b}{2}\right)^{(2 n+1) / n}\left(\frac{\Delta P}{k L}\right)^{1 / n}
$$

where the flow rate $Q=A_{\mathrm{p}} v_{\mathrm{p}}$, with $A_{\mathrm{p}}$ the slit cross section area and $v_{\mathrm{p}}$ of the piston speed.

Finally, the flow strength is characterized by the Weissenberg number based on molecular stretch relaxation time ${ }^{41}$

$$
W i_{\text {stretch }}(y)=\dot{\gamma}(y) \times \tau_{\text {s }}
$$

and the work applied during flow, assuming stationary flow, is given by

$$
\operatorname{work}(y)=\sigma(y) \gamma(y)=\sigma(y) \dot{\gamma}(y) \times \frac{\text { displacement }}{v_{\mathrm{p}}}
$$

Flow Conditions. The step shear experiments, performed at $165^{\circ} \mathrm{C}$, are characterized by a piston displacement of $3 \mathrm{~mm}$, a piston speed $\left(v_{\mathrm{p}}\right)$ varying from 2 to $16 \mathrm{~mm} / \mathrm{s}$, and the shear time that varies accordingly $\left(t_{\mathrm{s}}=\right.$ displacement $\left./ v_{\mathrm{p}}\right)$. Details are given in Table 1 .

During flow the pressure difference between the ends of the slit $\Delta P$ increases (see Figure 2). Notice that $t=0$ is defined at the moment

\begin{tabular}{|c|c|c|c|c|c|}
\hline \multicolumn{3}{|c|}{ set parameters } & \multicolumn{3}{|c|}{ calculated flow parameters } \\
\hline $\begin{array}{l}\text { piston } \\
\text { speed } v_{p} \\
{[\mathrm{~mm} / \mathrm{s}]}\end{array}$ & $\begin{array}{c}\text { piston } \\
\text { displacement } \\
{[\mathrm{mm}]}\end{array}$ & $\begin{array}{c}\text { shear } \\
\text { time } \\
{[\mathrm{s}]}\end{array}$ & $\begin{array}{l}\text { wall shear } \\
\text { rate }\left[\mathrm{s}^{-1}\right]\end{array}$ & $\begin{array}{c}\text { wall } \\
\text { stress } \\
{[\mathrm{MPa}]}\end{array}$ & $\begin{array}{l}\text { pressure } \\
\text { drop } \Delta P \\
\quad[\text { bar }]\end{array}$ \\
\hline 16 & 3 & 0.188 & 1180 & 0.19 & 304 \\
\hline 8 & 3 & 0.375 & 590 & 0.14 & 225 \\
\hline 6 & 3 & 0.500 & 442 & 0.12 & 199 \\
\hline 4 & 3 & 0.750 & 295 & 0.10 & 167 \\
\hline 2 & 3 & 1.500 & 147 & 0.08 & 124 \\
\hline
\end{tabular}
flow stops. For the experiment with $v_{\mathrm{p}} \leq 8 \mathrm{~mm} / \mathrm{s}, \Delta P$ rapidly increases at the start of flow and after a small overshoot levels off to a steady state. Eventually, when flow ceases, $\Delta P$ relaxes back toward the original value. The steady values of $\Delta P$ are in good agreement with the

Table 1. Set and Calculated Flow Parameters as a Function of Critical Stresses at $165^{\circ} \mathrm{C}$

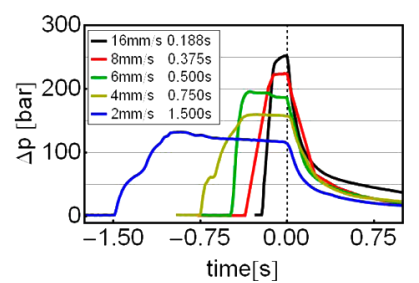

Figure 2. Pressure drops measured during the shear pulse at $165{ }^{\circ} \mathrm{C}$.

predictions of eq 5 (see Table 1 ), except for $v_{\mathrm{p}}=16 \mathrm{~mm} / \mathrm{s}$. Because of the short shear time (the shortest), flow cannot fully develop and a steady $\Delta P$ value is not reached. In this case, eq 5 overpredicts the measurement and the maximum $\Delta P$ reached during the experiment, i.e., $250 \mathrm{bar}$, is used for calculating the flow parameters. These values are shown in Figure 3.

The agreement between measurements and calculated $\Delta P^{\prime}$ s (at least for the cases with fully developed flow, i.e., $v_{\mathrm{p}} \leq 8 \mathrm{~mm} / \mathrm{s}$ ) indicates that during the brief flow pulse the flow behavior of the material is not affected by structure formation, if there is any at all. Therefore, flow parameters such as shear rate and stress can be calculated at each position in the slit using eqs 3 and 4 . Shear stress, shear rate, Weissenberg number for stretch, and work as a function of $v_{\mathrm{p}}$ and position are shown in Figure 3. With this different rheological classifications can be made. From here on, experiments are identified according to the wall shear stress, ranging from 0.08 to $0.16 \mathrm{MPa}$.

\section{RESULTS AND DISCUSSION}

The cross section of an iPP specimen solidified after shear at high temperature $\left(16 \mathrm{~mm} / \mathrm{s}\right.$ for $0.188 \mathrm{~s}$ at $\left.165{ }^{\circ} \mathrm{C}\right)$ shows varying structural characteristics as shown in Figure 4. Clearly, the size and morphology of the formed crystallites are strongly position-dependent. Around the centerline (reference position), large spherulites, with diameters in the order of $0.1 \mathrm{~mm}$, are observed. Toward the walls of the slit $( \pm 0.75 \mathrm{~mm})$, the spherulite size decreases until, at about $\pm 0.70 \mathrm{~mm}$ where the stress reaches $\sim 0.14 \mathrm{MPa}$, the morphology suddenly changes. At this point, spherulites are replaced by highly birefringent shish-kebab structures oriented along the flow direction. This varying morphology arises from the varying flow strength in the slit. ${ }^{42}$ Close to the centerline, stress is low so the relaxed coiled conformation of molecules is essentially unperturbed during flow, and the crystallites, which develop when the sample is cooled to room temperature, tend to grow equally in all directions and give rise to spherulites, similar to crystallization in the absence of flow.

Moving away from the centerline, stress increases and the average molecular conformation during flow gradually deviates from the random coil. The first deformation process is the preferential orientation of molecular segments. This can dramatically enhance the nucleation density while affecting the tendency of the crystallites to grow in all directions only to a limited extent. ${ }^{43}$ As a result, spherulites are still the building blocks of the morphology, but their number density increases (or equivalently: their diameter decreases). Close to the walls of the slit, the high stress promotes, besides orientation, also stretch of molecular segments. In these conditions nucleation becomes so fast that the average anisotropic conformation that molecules adopt during flow is frozen-in in oblong crystallites (shish) before relaxation starts. Shish crystals are very efficient in promoting the crystallization of lamellar stacks with normal parallel to the flow direction (kebab) due to their perfect lattice matching. The growth of lamellar stacks can also be accelerated by molecules that are partially involved in the shish backbones 

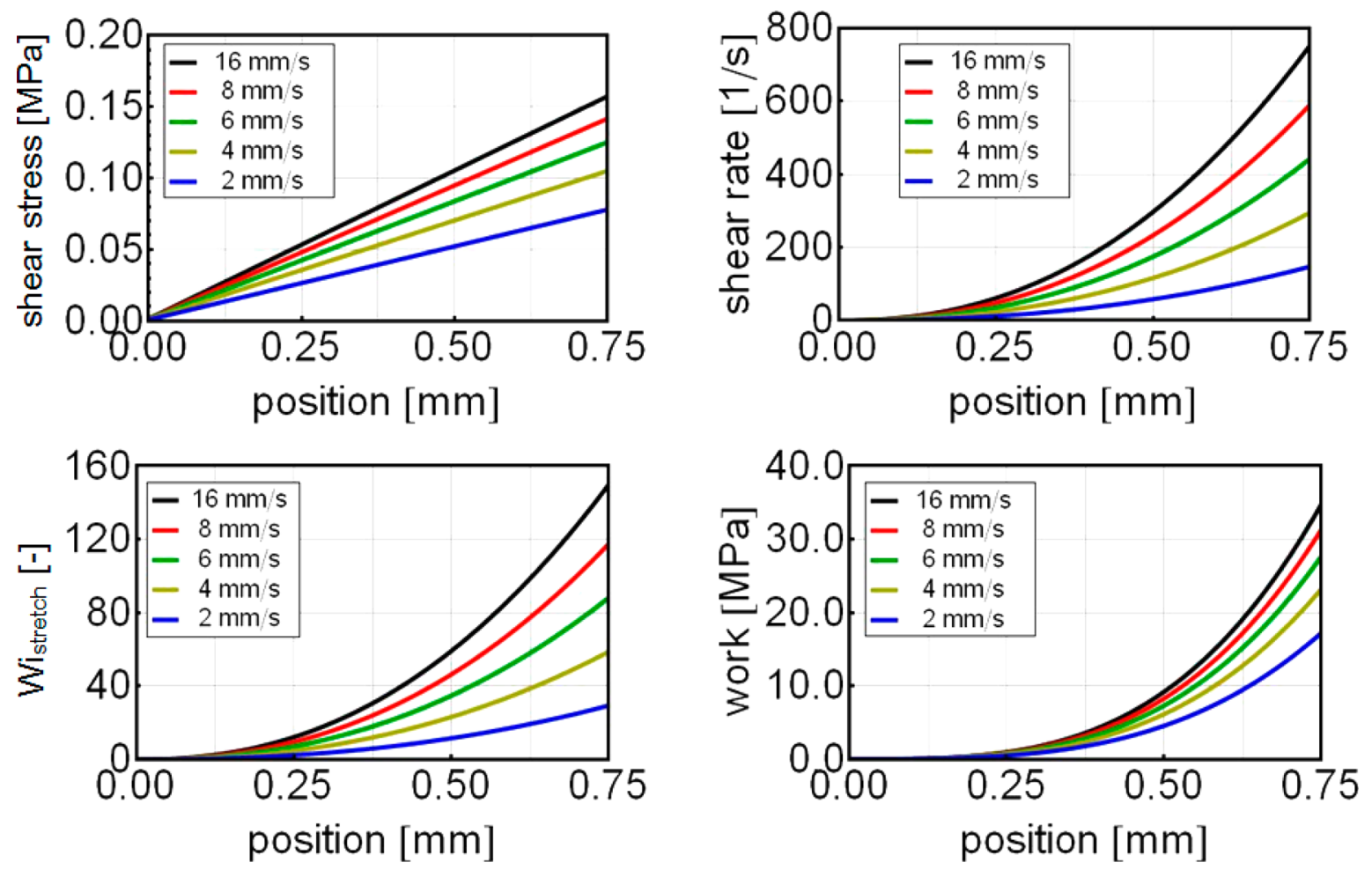

Figure 3. Flow parameters as a function of the distance from the centerline. Notice that the flow conditions resemble those of real-life processing operations.

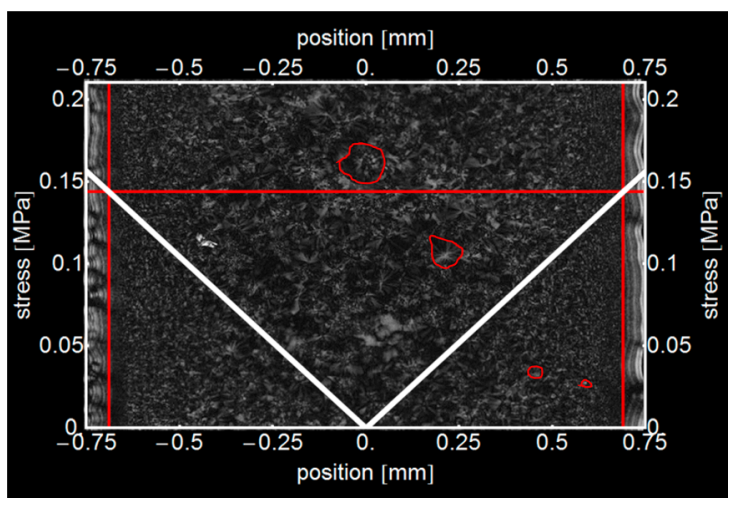

Figure 4. Optical micrograph of a specimen crystallized under the influence of a shear pulse with a piston speed of $16 \mathrm{~mm} / \mathrm{s}$ for $0.188 \mathrm{~s}$ at $165{ }^{\circ} \mathrm{C}$. Red lines indicate the shear layer and typical sizes of spherulites; white lines indicate the shear stress profile. and therefore have limited mobility. ${ }^{44,45}$ The layer with shishkebabs is often called the "shear layer". Kumaraswamy et al. ${ }^{46}$ showed that the shear layer forms only when the local stress exceeds a critical value that is a characteristic for the material used and its molecular weight distribution. This is equivalent to state that the formation of shish-kebabs takes place only when the average molecular deformation is sufficiently high. The critical stress for the iPP investigated here is $0.14 \mathrm{MPa}$.

It should be noted that structures in the inner layer, i.e., between the shear layers (see Figure 4), includes not only isotropic spherulites but also mildly oriented crystallites. The appearance of mildly oriented crystallites results from the gradual decrease of shear strength from the wall to the centerline. These crystallites are indeed oriented but are not sufficient to induce appearance of shish kebab. Comparison between experimental and modeling results done by Custodio

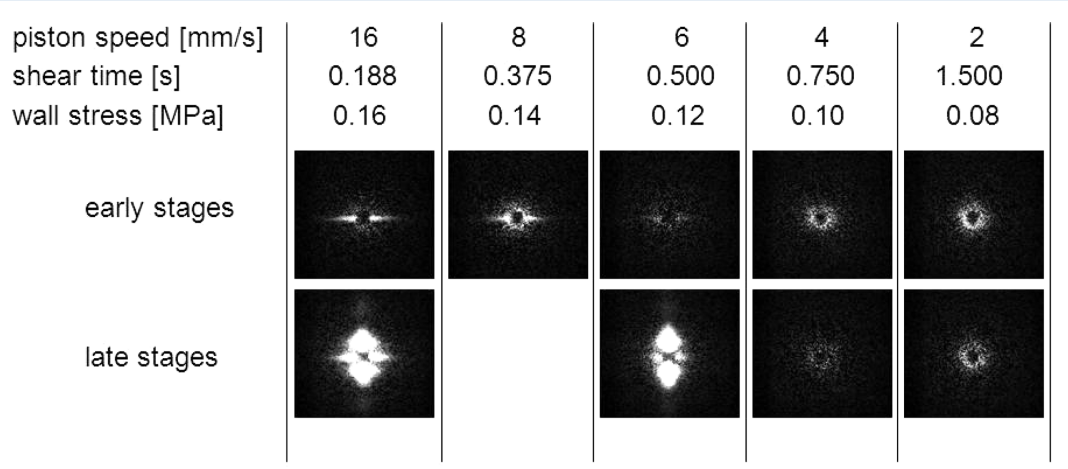

Figure 5. Early stages: first image after flow, late stages: last image of the experiment at $165{ }^{\circ} \mathrm{C}$. The flow conditions are given above SAXS images, and flow direction is vertical. 
et al. ${ }^{47}$ suggested that the length of oriented nuclei per volume is the dominant parameter.

To investigate the formation of shish-kebabs without having to deal with the complexity of the multilayered morphology as shown Figure 4, we choose to perform a series of isothermal step shear (or shear pulse) experiments at a high temperature, $165{ }^{\circ} \mathrm{C}$, just about the nominal melting point. Here, at sufficiently high stresses, only the shear layer forms crystallites while the rest of the material, weakly affected by flow, remains molten. As discussed later, this circumstance simplifies the interpretation of X-ray scattering data.

Fibrillar Density Fluctuation: Stabilization and Formation of Crystalline Segments. SAXS patterns representative of the early and late stages of isothermal crystallization experiments at $T=165{ }^{\circ} \mathrm{C}$ are shown in Figure 5. These images reveal that there is a clear distinction between experiments with wall stress above and below $0.12 \mathrm{MPa}$. When $\sigma_{\mathrm{w}} \geq 0.12 \mathrm{MPa}$, the streak-like equatorial intensity in the early stages indicates the formation of density fluctuations (shish) with a high aspect ratio and oriented along the flow direction. The lack of an interference maximum along the equator suggests that the lateral packing of these density fluctuations is irregular, characterized by a very large spread or very large distance (above $100 \mathrm{~nm}$ ), i.e., beyond detection limit of the SAXS setup used here. Moreover, for these high stresses, a meridional interference peaks develop over time, indicating crystallization of lamellar stacks perpendicular to the flow direction (kebab).

In contrast, at low stresses, when $\sigma_{\mathrm{w}}<0.12 \mathrm{MPa}$, the scattering patterns remain essentially featureless during the whole experimental time (about $10^{3} \mathrm{~s}$ ).

Figure 5 clearly demonstrates that for this particular iPP grade there is a threshold stress $\sigma_{\mathrm{c}}=0.12 \mathrm{MPa}$ for the formation of shish-kebabs at $165{ }^{\circ} \mathrm{C}$. Below this critical stress and within the experimental time of about $10^{3} \mathrm{~s}$, crystallization does not take place at all. It is important to notice that the value of $\sigma_{\mathrm{c}}$ obtained from Figure 5 is lower than expected from the thickness of the shear layer in Figure 4. However, the optical visible oriented layer in Figure 4 is not necessarily the only part of the sample containing shish-kebabs. "Optical visible" is different from "X-ray detectable"; also, outside the visible shear layer shish-kebabs might be present, smaller, less dense, and possibly mixed with spherulites. Independently of the particular choice of $\sigma_{\mathrm{c}}$ (between 0.12 and $0.14 \mathrm{MPa}$ ), the images of Figure 5 confirm that the formation of shish-kebabs takes place only in a (thin) layer close to the wall, where stress exceeds $\sigma_{\mathrm{c}}$. From here on we will use the critical stress determined from X-ray measurements.

It should be noted that the total strain at the wall $\left(\varepsilon_{\mathrm{w}}=\dot{\gamma}_{\mathrm{w}} \times\right.$ $\left.t_{\mathrm{s}}\right)$ is the same for all experiments, fixed to about 220, as listed in Table 1. Therefore, we do not discuss the influence of strain on flow-induced crystallization. On the other hand, the mechanical work often serves as the threshold parameters for appearance of oriented crystallites or onset of accelerated crystallization kinetics. ${ }^{48,49}$ Since an identical wall strain $\varepsilon_{\mathrm{w}}$ was employed, the dependence of flow-induced crystallization on the work $\left(\sigma_{\mathrm{w}} \times \varepsilon_{\mathrm{w}}\right)$ is consistent with using the stress $\sigma_{\mathrm{w}}$.

The existence of a critical stress $\sigma_{\mathrm{c}}$ reveals that fibrillar precursors are formed when the average molecular deformation is sufficiently high. Therefore, it seems reasonable to propose that they form during the shear pulse or, in other words, when the deformation mechanism is still in place and before complete relaxation of stretched chains occurs. This is also in line with the results in Figure 5 showing that the equatorial streak is either present immediately after flow or completely absent during the experiment. Ultimately, this consideration indicates that what happens during flow (or immediately after) defines the thickness of the shear layer and this value is not going to change with time. This is especially important for the following discussion on the SAXS patterns.

The radius $R$ of the fibrillar scatterers can be measured from the slope of the intensity scattered at low angles:

$$
I(s) \propto \frac{1}{s} \exp \left(-2 \pi^{2} R_{\mathrm{c}}{ }^{2} s^{2}\right)
$$

where $R_{c}$ is the radius of gyration of the cross section $\left(R_{c}=R /\right.$ $\sqrt{ } 2)$. Within this limit, $\ln [I(s) \cdot s]$ versus $s^{2}$ is a straight line with a slope $-2 \pi^{2} R_{c}{ }^{2}{ }^{50} \mathrm{~A}$ Guinier analysis of the equatorial streak (examples shown in Figure 6) indicates that when the fibrillar

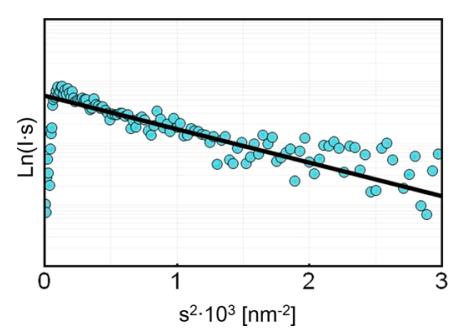

Figure 6. Guinier plot of the lowest angle part of SAXS curves for 0.16 $\mathrm{MPa}$ at $165^{\circ} \mathrm{C}$.

density fluctuations are assimilated to cylinders, their diameter is $\sim 25 \mathrm{~nm}$, independent of the flow conditions. Assuming an average distance between molecules in the order of $5 \AA$ (typical crystalline lattice value), this means that the cross section of the fibrillar objects contains in the order of $10^{3}$ molecular stems. Based on this, it is reasonable to consider the formation of fibrillar density fluctuations as a co-operative process that involves many molecules.

To our knowledge, the structural element that keeps these molecules from relaxing and the density fluctuations from dissolving has not been conclusively identified in the literature. To address this point, the experiments of Figure 5 are also performed in combination with WAXD. Remarkably, when $\sigma_{\mathrm{w}}$ $\geq 0.12 \mathrm{MPa}$, in spite of the high temperature $\left(165{ }^{\circ} \mathrm{C}\right)$, diffraction from highly oriented crystals is detected already in the first image after flow. This indicates that the "glue" keeping molecules from relaxing is crystallization of certain sections of the fibrillar density fluctuations. The level of crystallinity is too low to be quantified, indicating that these crystalline sections are small and sporadic. Nevertheless, the signals of the intensity scans through equator, presented in Figure 7, are quite clear.

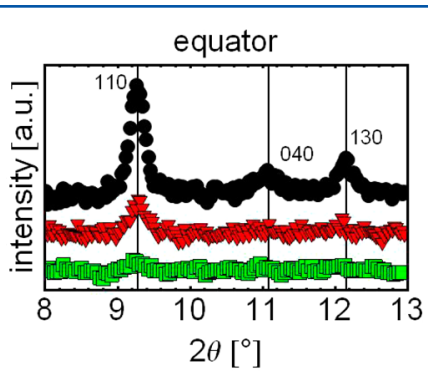

Figure 7. WAXD profiles taken through the equator in the first image after flows of $0.16 \mathrm{MPa}$ (top, black circle), 0.14 MPa (middle, red triangle), and $0.12 \mathrm{MPa}$ (bottom, green square) at $165{ }^{\circ} \mathrm{C}$. 
The observed Bragg peaks indicate that the crystalline sections have the structure of the alpha form of iPP. The intensities decrease together with wall stress, suggesting that the occurrence of crystalline sections becomes less frequent at lower stress. Eventually, when $\sigma_{\mathrm{w}}<0.12 \mathrm{MPa}$, no Bragg peaks are observed.

These observations indicate that when stress exceeds 0.12 $\mathrm{MPa}$, molecular orientation and stretch introduce so much local order that small regions of crystallinity are formed and stabilize the fibrillar density fluctuations keeping molecules from relaxing.

The experimental temperature of $165{ }^{\circ} \mathrm{C}$ is lower than the equilibrium melting temperature of isotactic polypropylene $\left(187^{\circ} \mathrm{C}\right)$; thus, stable crystallites can be formed that restrict chain segmental movement and prevent molecules to detach from shish. The recent work by Ma et al. ${ }^{51}$ shows that shish first relax into SAXS undetectable precursors instead of random coils. Therefore, it should be pointed that the stabilization mechanism proposed above is only for the transition from shish into SAXS undetectable precursors. The stability of flowinduced precursors, which are often undetectable by SAXS, is not further discussed in this work. The lifetime of these precursors can be hours even above the equilibrium melting temperature, ${ }^{27}$ which indicates that some still unknown factor other than crystalline dominates the stability of SAXS undetectable precursors.

To investigate the evolution of density fluctuations into the final morphological building blocks, SAXS images are analyzed as a function of time. In particular, the time evolution of the equatorial SAXS intensity is shown in Figure 8.

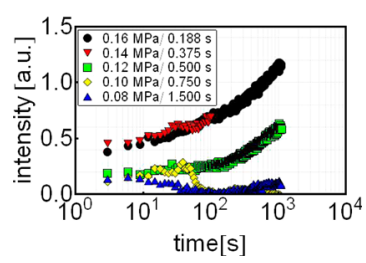

Figure 8. Overall SAXS equatorial intensity as a function of time at $165{ }^{\circ} \mathrm{C}$.

When $\sigma_{\mathrm{w}} \geq 0.12 \mathrm{MPa}$, the equatorial streaks are the only SAXS features until $\sim 200 \mathrm{~s}$, and interestingly, its intensity increases significantly over time. Moreover, after $200 \mathrm{~s}$ also the meridional lobes become visible. Having already excluded the formation of fibrillar precursors after flow, the increase of the equatorial intensity can only be explained assuming that they crystallize further. Despite the high temperature, crystal growth can still take place because molecules are immobilized in stretched conformations by the crystalline sections distributed along the fibrils' axes. This makes the longitudinal direction the only possible growth direction.

The model for the formation of shish that emerges from the above considerations is pictorially summarized in Figure 9. Deformed molecules form densely packed precursors. Since molecular orientation and stretch reduce the entropy change required for crystallization and the corresponding increase of the melting temperature cause a larger degree of undercooling for the polymers under isothermal condition, ${ }^{52}$ the precursors can (locally) crystallize. However, it is unlikely that molecules have sufficient time to disentangle to pack into ideal crystallites. Entanglements, jogs, and kinks behave as defects during the subsequent crystallization of shish. These defects are laterally

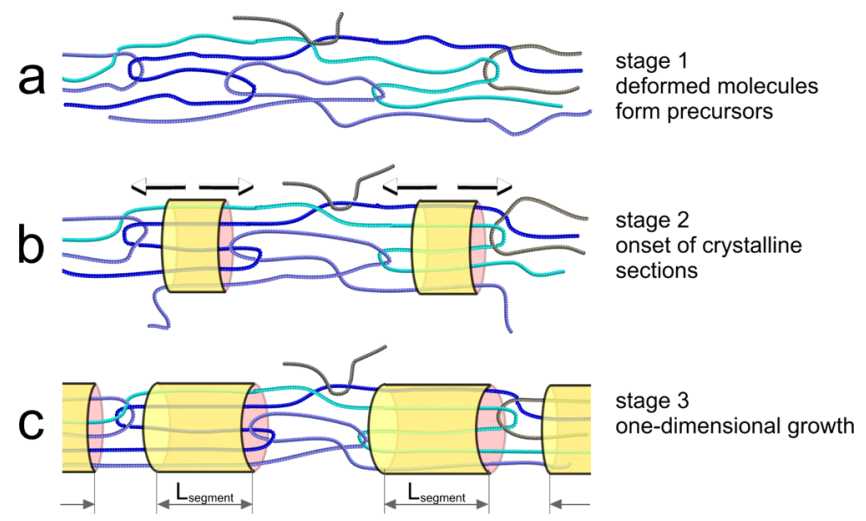

Figure 9. Pictorial description of the two-phase model for the formation of shish of isotactic polypropylene.

restricted and only mobile along longitudinal chain direction. The growth fronts expel defects from the crystallization region into the region between two opposite growing fronts. The accumulation of defects does not allow crystallization in these regions, forming defective and noncrystalline sections within shish. This model is similar to that proposed by Petermann et al. ${ }^{31}$ but without longitudinal periodicity. It gives to crystalline sections the role of connected "flow-induced nuclei" that can grow because of the restricted molecular configuration along the axis of oblong density fluctuations that play the role of "mesophases". Moreover, Lieberwirth et al. ${ }^{53}$ observed the ends of shish can grow outward into the melt, even the melt is undeformed. Considering that a single shish has only two ends and much more crystallizing sections, the increases of SAXS signal is dominated by the crystallization of internal ordered sections. When the crystalline sections growing inside shish become stable, they will nucleate lateral growth of kebab.

In the literature, an alternative model has been proposed for shish formation. ${ }^{54}$ Mykhaylyk et al. described the shish formation as a four-step process, including stretching, nucleation, alignment, and fibrillation. It was suggested that stable nuclei are formed first, and their subsequent alignment favors formation of fibrillar nuclei. Therefore, the major difference between the current model and Mykhaylyk's model is about the sequence of formations of stable nuclei and fibrillary shish: (1) stable nuclei are formed first and then shish build up, or (2) shish are formed first and then stable nuclei develop internally.

Here, we have (arbitrarily) assumed that the first step is the formation of an "amorphous" density fluctuation. In reality, it could also be that the formation of a crystalline section takes place first and, by restricting the conformation of molecules, promotes further stretching and formation of more crystalline sections. The data at hand do not conclusively support either of these two scenarios.

To conclude, it is worth noticing that density fluctuations are formed also when $\sigma_{\mathrm{w}}<0.12 \mathrm{MPa}$. This is indicated by the increased scattered intensity. However, there are clear distinctions with the experiments at higher stress. For instance, the scattered intensity is azimuth-independent at low angles (notice the meridional intensity of Figure 4 being the similar as the equatorial), suggesting that the aspect ratio of density fluctuations is in these cases rather small (about unity). On top of that, these density fluctuations bear no signs of crystallinity (no Bragg peaks observed in WAXD) and are therefore 
unstable. At $\sim 60 \mathrm{~s}$, they dissolve lowering the scattered intensity until the reference value.

Growth of Lamellae Stacks. To investigate the growth of stacks of lamellae, the experiments with $\sigma_{\mathrm{w}} \geq 0.12 \mathrm{MPa}$ are examined in more detail. When the crystalline segments within shish are sufficiently long, they become an ideal substrate for the heterogeneous nucleation of stacks of lamellae with molecules that could also be partially included within the fibril. The epitaxial relation with the crystalline segments is such that lamellae grow with normal parallel to the fibrils' axes (flow direction). Stacks of lamellae with this orientation produce an interference peak in the meridian of SAXS images. Figure 10

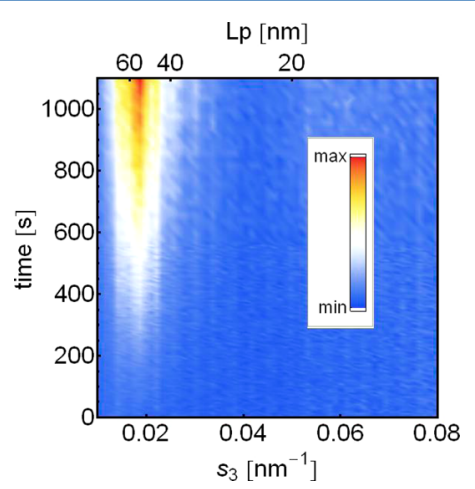

Figure 10. Meridional SAXS intensity as a function of time for the experiment with $\sigma_{\mathrm{w}}=0.16 \mathrm{MPa}$ and shear time $0.188 \mathrm{~s}$.

shows that for the experiment with $\sigma_{\mathrm{w}}=0.16 \mathrm{MPa}$ and shear time $0.188 \mathrm{~s}$ this peak become visible just after $200 \mathrm{~s}$, and its time-independent position corresponds to a long period of 58 $\mathrm{nm}$.

As shown in Figure 11, the growth of stacks of lamellae leads to a sharp increase of the meridional scattered intensity. The kinetics of this process is similar for all the experiments with $\sigma_{\mathrm{w}}$ $\geq 0.12 \mathrm{MPa}$.

The growth of the kebabs can be analyzed by modeling the SAXS meridional intensity as a function of time. A valuable approach to this problem has been proposed by the group of Hsiao $^{55,56}$ and is based on the factorization of the scattered intensity in structure and form factor. ${ }^{57,58}$ Approximating kebabs to be stacks of perfectly aligned and polydispersed disks, the scattered intensity can be expressed as

$$
\begin{aligned}
& I\left(s_{12}, s_{3}\right) s_{3}^{2}=K\left[\left\langle\left|A\left(s_{12}, s_{3}\right)\right|^{2}\right\rangle_{D, T}-\left|\left\langle A\left(s_{12}, s_{3}\right)\right\rangle_{D, T}\right|^{2}\right. \\
& \left.\quad+\left|\left\langle A\left(s_{12}, s_{3}\right)\right\rangle_{D, T}\right|^{2}\left|Z_{L}\left(s_{3}\right)\right|^{2}\right]
\end{aligned}
$$

where $K$ is a proportionality constant, $A\left(s_{12}, s_{3}\right)$ is the form factor, $Z_{L}\left(s_{3}\right)$ is the structure factor, and $s_{12}$ and $s_{3}$ are the components of $s$ in the equatorial and meridional directions, respectively. When the generalized $\Gamma$-distribution is employed to describe the distribution functions of the long period, diameter $D$, and thickness $T$ of the kebabs, eq 9 has an analytical expression (further details can be found in the original contributions) and can readily be used to fit a set of meridional intensity slices ( $I$ vs $s_{3}$ at constant $s_{12}$ ) and so obtain the dimensions that characterize kebabs. The good agreement typically found between the fit and the experiments is shown in Figure 12.

The average size of the kebabs, obtained from fitting, is plotted in Figure 13 as a function of time. As expected, based on the isothermal conditions, thickness and long period do not vary with time. Nevertheless, a major change is observed in the diameter of the kebab. The bidimensional growth rate emerging from this data, $G_{2 \mathrm{D}} \approx 0.1 \mathrm{~nm} / \mathrm{s}$, is nearly a factor 10 higher than expected from quiescent crystallization $\left(G_{2 D} \mathrm{Q}=0.01 \mathrm{~nm} / \mathrm{s}\right)$, indicating that shear has a large influence on growth kinetics of kebabs as well. In a recent paper by Roozemond et al., ${ }^{45}$ it was shown that such an increased lateral growth rate of kebab is essential for predicting the evolution of shish-kebab growth. The radial growth of the kebabs does not last indefinitely. At $\sim 600 \mathrm{~s}$, impingement takes place, and the diameter of the kebabs reaches the maximum value of $\sim 90 \mathrm{~nm}$.

The final diameter of the kebabs is also a measure for the lateral distance between shish. The lateral packing of shishkebabs is most probably irregular. However, assuming a hexagonal packing allows estimating that shish occupy only about 7 vol \% of the shear layer in the experiment with 0.16 MPa wall stress:

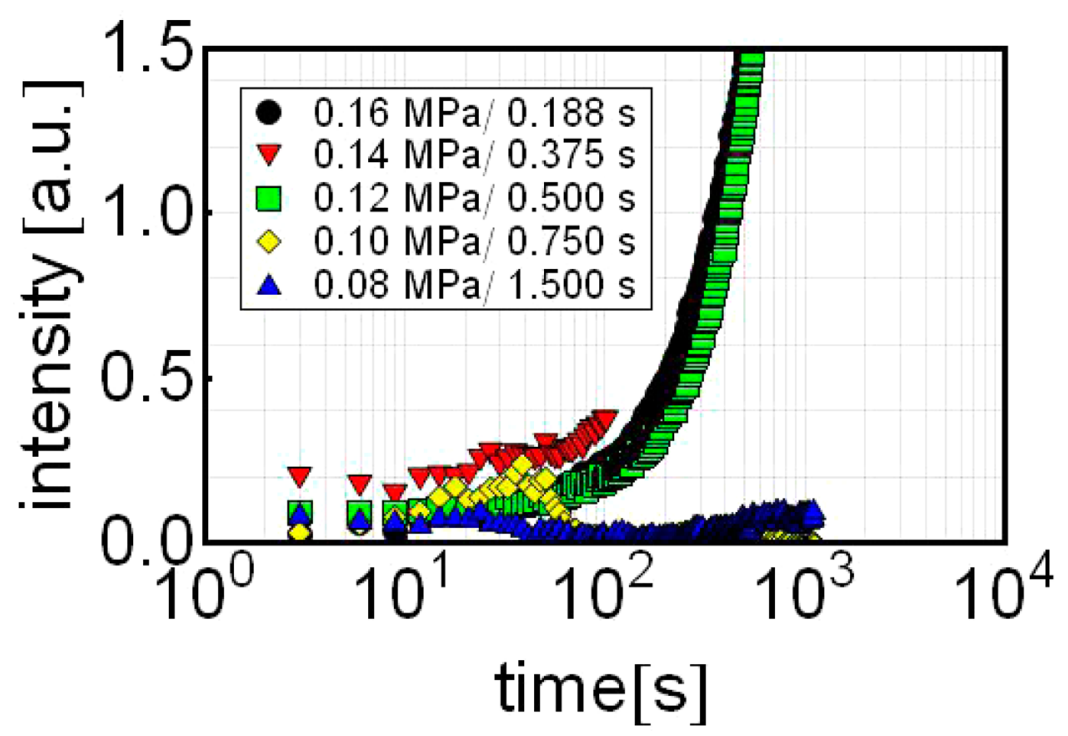

Figure 11. Overall SAXS meridional intensity as a function of time. 

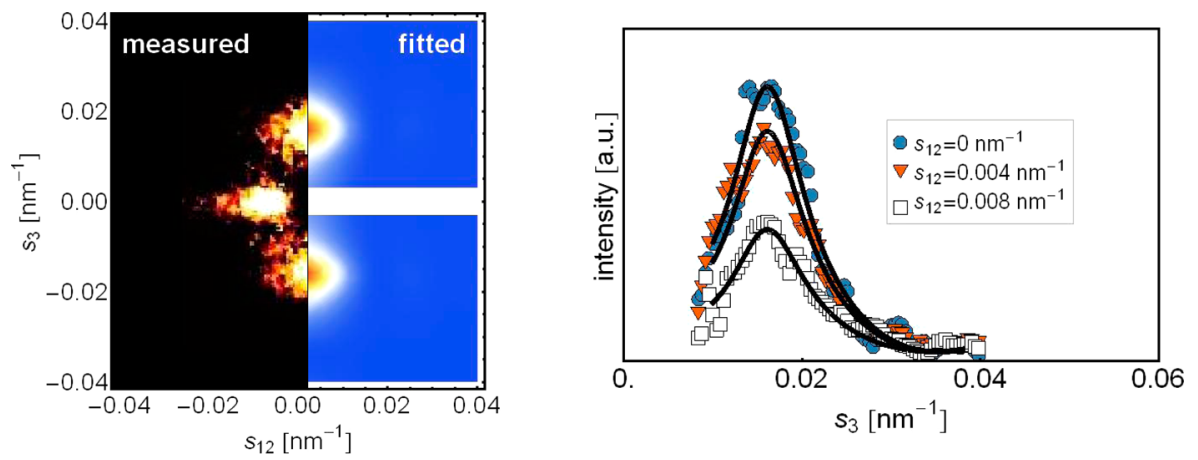

Figure 12. Comparisons between experimental data and fitted model (eq 9) represented in one and two dimensions for $0.16 \mathrm{MPa}$ at $165{ }^{\circ} \mathrm{C}$.

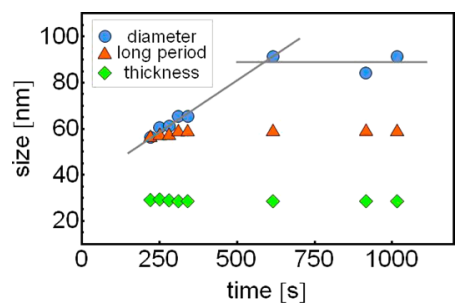

Figure 13. Average sizes characterizing kebabs obtained via fitting the SAXS meridional intensity for $0.16 \mathrm{MPa}$ at $165^{\circ} \mathrm{C}$.

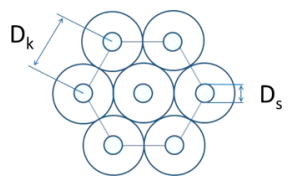

Figure 14. Schematic and hypothetical hexagonal packing of shishkebab.

$$
\begin{gathered}
V_{\text {shishes }}=100 \% \times \frac{3 \cdot \text { area shish }}{\text { area hexagon }}=100 \% \\
\times \frac{3 \pi D_{\text {shish }}{ }^{2} / 4}{(3 \sqrt{3} / 2) D_{\text {kebab }}^{2}} \approx 7 \%
\end{gathered}
$$

Validation of the Molecular Model. The conceptual molecular model proposed above implies that during the transformation of flow-induced precursors into shish-kebabs there are two stages with well-defined growth kinetics: (1) onedimensional growth kinetics due to the formation of crystalline segments within shish and (2) two-dimensional growth kinetics due to the growth of lamellar stacks.

To validate the model, we analyze the overall crystallization kinetics as measured by WAXD. In particular, the focus is on the two experiments with the highest stress because of the favorable intensity of the signal. The measured WAXD crystallinity indices are shown in Figure 15. Because of the layer structure of the specimen (skin layer + core), these values are not the local crystallinity index $x(t)$ in certain specific shear layer with the thickness of $T_{\text {shearlayer, }}$ but averaged over the optical pathway of the X-ray through the whole sample. Therefore, they are referred to as apparent crystallinity indices $x_{\text {app }}(t)$.

Considering the optical path of the X-ray beam in relation to the shear layer, it is straightforward to conclude that

$$
x_{\text {app }}(t)=2 \frac{T_{\text {shear layer }}}{T_{\text {tot }}} x(t)
$$

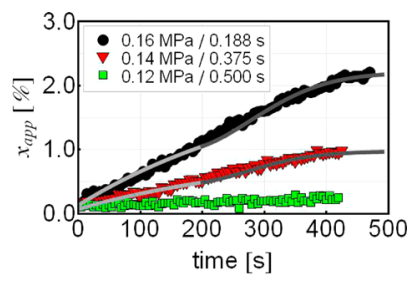

Figure 15. Apparent crystallinity index (from WAXD) for the experiments where $\sigma_{\mathrm{w}} \geq 0.12 \mathrm{MPa}$. The gray lines are the apparent crystallinities calculated with eq 11, using the fitting parameters given in Table 2.

where $T_{\text {tot }}(=1.5 \mathrm{~mm})$ is the total thickness of the sample. For an apparent crystallinity of $2 \%$ we get a real crystallinity in shear layer of $30 \%$, clearly in the range for impingement. This apparent crystallinity index $x_{\text {app }}$ can be used to define an apparent space filling $\Phi_{\text {app }}$. Interestingly, as $T_{\text {shear layer }}$ is constant over time, $\Phi_{\text {app }}(t)$ coincides with the local space filling within the shear layer $\Phi$ :

$$
\Phi_{\mathrm{app}}(t)=\frac{x_{\mathrm{app}}(t)-x_{\mathrm{app}}\left(t_{0}\right)}{x_{\mathrm{app}}\left(t_{\infty}\right)-x_{\mathrm{app}}\left(t_{0}\right)}=\frac{x(t)-x_{0}}{x_{\infty}-x_{0}}=\Phi(t)
$$

The evolution of space filling over time for the experiments with 0.16 and $0.14 \mathrm{MPa}$ wall stress is shown in Figure 16.

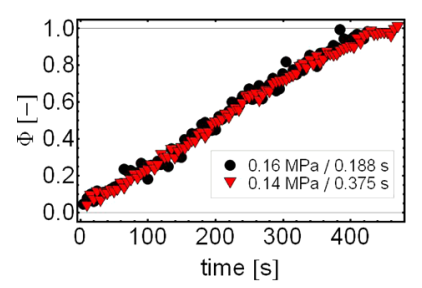

Figure 16. Space filling (in the shear layer) as a function of time obtained from WAXD data.

Remarkably, the two data sets superimpose, providing a strong indication that the crystallization kinetics is the same in both cases. Similarly, Roozemond et al. ${ }^{45,59,60}$ also reported that crystallization kinetics is almost the same for several severe flow conditions. The differences measured in the absolute value of $x_{\text {app }}$ can be ascribed solely to a different thickness of the shear layer. In this light, we also conclude that the crystallization kinetics is homogeneous through the shear layer.

Based on the interpretation of the SAXS data, the mechanisms that contribute to space filling are:

- Longitudinal growth of crystalline sections within the fibrillike shish. The unidirectional propagation of the growth front 
along the fibrils' axes makes the crystallized volume increase linearly with time:

$$
V_{1}(t)=\left[2 N_{1} \pi(D / 2)^{2} G_{1 D}\right] t=k_{1} t
$$

where $N_{1}$ is the number of crystalline sections that grow, $D$ the diameter of fibrils, and $G_{1 D}$ the shish growth rate, assumed to be constant. Note that the factor 2 in eq 13 is due to the longitudinal growth on both sides of crystalline sections.

- Radial growth of disk-like lamellae. In this case, with a twodimensional growth front, the crystallized volume increases quadratically with time. Moreover, the onset of the SAXS meridional peak suggests that this process becomes active only after $t_{0} \sim 200 \mathrm{~s}$. Therefore

$$
V_{2}(t)=\left(N_{2} \pi T G_{2 \mathrm{D}}^{2}\right) U\left(t-t_{0}\right)\left(t-t_{0}\right)^{2}=k_{2} U\left(t-t_{0}\right)\left(t-t_{0}\right)^{2}
$$

where $N_{2}$ is the number and $T$ the thickness of lamellae, $G_{2 D}$ the kebab growth rate that is assumed to be constant (i.e., an average value), and $U\left(t-t_{0}\right)$ the unit step function.

Overall, following the reasoning of Avrami, ${ }^{61}$ the space filling or the probability that a certain point in a unit volume of the material falls within the crystallized volume is given by

$$
\begin{aligned}
& \Phi(t)=1-\exp \left[-V_{1}(t)-V_{2}(t)\right] \\
& \quad=1-\exp \left[-k_{1} t-U\left(t-t_{0}\right) k_{2}\left(t-t_{0}\right)^{2}\right]
\end{aligned}
$$

and rearranging

$$
-\ln [1-\Phi(t)]=k_{1} t+U\left(t-t_{0}\right) k_{2}\left(t-t_{0}\right)^{2}
$$

Equation 16 predicts that $-\ln [1-\Phi(t)]$ increases linearly as a function of time for $t<t_{0}$ and quadratically for $t \geq t_{0}$. The rather good agreement between these predictions and the measured data, observed in Figure 17, supports the kinetic
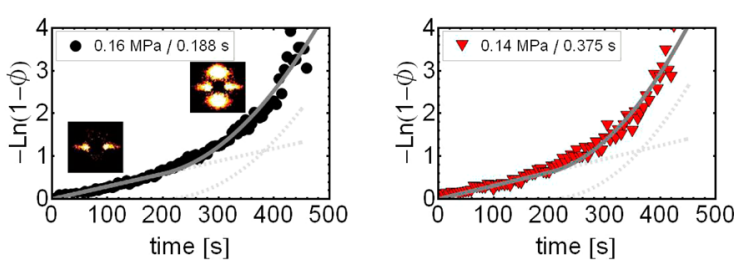

Figure 17. Modified Avrami plots where the experimental data are compared with a model containing a linear and a quadratic contribution to space filling as a function of time. The two kinetic contributions are represented by the dashed lines.

hypotheses and, eventually, the mechanistic model that we have put forward. The fits of Figure 17 also show that the linear growth of crystalline segments within shish continues for $t>$ $200 \mathrm{~s}$ when also the kebabs grow.

The best-fit parameters for the two experiments are provided in Table 2. Using these parameters, a good description of the time evolution of the apparent crystallinity $x_{\text {app }}$ (solid lines in Figure 15) can be obtained combining eqs 12 and 15.

Table 2. Parameters Obtained Comparing Eq 16 with Experimental Data

\begin{tabular}{lclccc} 
& $x_{0}$ & $x_{\infty}$ & $k_{1}\left[\mathrm{~nm}^{3} \mathrm{~s}^{-1}\right]$ & $k_{2}\left[\mathrm{~nm}^{3} \mathrm{~s}^{-2}\right]$ & $t_{0}[\mathrm{~s}]$ \\
\hline $0.16 \mathrm{MPa}$ & 0.13 & 2.2 & $2.9 \times 10^{-3}$ & $3.4 \times 10^{-5}$ & 200 \\
$0.14 \mathrm{MPa}$ & 0.07 & 0.97 & $3.1 \times 10^{-3}$ & $4.2 \times 10^{-5}$ & 200
\end{tabular}

\section{CONCLUSIONS}

The analysis of stress-induced crystallization in a slit flow by means of X-ray scattering proves that iPP can crystallize in the form of shish-kebabs at temperatures as high as $165{ }^{\circ} \mathrm{C}$. This happens only when a threshold stress is overcome and, therefore, only in a layer close to the wall of the slit. At such a high temperature, the thickness of the shear layer does not vary with time, and this simplifies the interpretation of the scattering results. Combining the observations coming from time-resolved SAXS and WAXD provides a clear picture of the whole crystallization process, in line with nucleation and growth theory. At low stress, unstable point-like density fluctuations are formed and due to the lack of stabilizing factors survive only for $\sim 50 \mathrm{~s}$. At high stress, oblong (fibril-like) density fluctuations are stabilized by small crystalline sections, distributed along the fibrillar axis, from the very early stages. These crystalline sections connect molecules in the longitudinal direction and allow them to retain stretched configurations for long times. Such restricted configurations promote crystallization despite the high temperature. The fibrils' axes become the preferential growth direction. The growth front propagates expelling (in the longitudinal direction) entanglements out of crystallization region and other lattice defects, thus giving rise to crystalline segments along the fibril axis. The high concentration of defects accumulated in between consecutive segments does not allow molecules to crystallize in these domains. Therefore, longitudinal molecular connectivity gives rise to a mechanism that transforms fibril-like density fluctuations in shish with alternating crystalline and amorphous segments. Eventually, shish occupy about $7 \%$ of the volume of the shear layer.

When the crystalline segments within shish are sufficiently long, they start promoting nucleation and growth of kebabs, stacks of lamellae oriented in the flow direction. In this way, crystallization speeds up, and despite the high temperature, the shear layer fills up.

This model for the formation of shish-kebab suggests a twostep growth process for space filling kinetics: linear time dependence during the first stage, when the crystalline segments of shish are formed, and quadratic time dependence in the second stage, when kebabs grow. The experimental validation of these features represents a strong proof that the proposed model is a sound mechanistic description of the sequence of events that leads to the formation of shish-kebabs.

\section{AUTHOR INFORMATION}

\section{Corresponding Authors}

*(Z.M.) E-mail: zhe.ma@tju.edu.cn.

*(G.W.M.P.) E-mail g.w.m.peters@tue.nl.

\section{Present Addresses}

L.B.: DSM Ahead, Urmonderbaan 22, 6167RD Geleen, The Netherlands.

D.C.: Department of Chemistry and Industrial Chemistry, University of Genova, via Dodecaneso, 31, 16146 Genova, Italy. T.B.v.E.: SABIC Innovative Plastics, Plasticslaan 1, P.O. Box 117 NL, 4600 AC Bergen op Zoom, The Netherlands.

L.F.-B.: Department of Mechanical and Materials Engineering, University of Nebraska, Lincoln, NE 68588.

\section{Notes}

The authors declare no competing financial interest. 


\section{ACKNOWLEDGMENTS}

NWO (Nederlandse Organisatie voor Wetenschappelijk Onderzoek) and ESRF are acknowledged for granting the beamtime. This work was part of the research program of the Dutch Polymer Institute (DPI), PO Box 902, 5600 AX Eindhoven, The Netherlands, projects \#634 and \#714. Z.M. appreciates the financial support from the National Natural Science Foundation of China (51573132).

\section{REFERENCES}

(1) Peters, G. W. M.; Balzano, L.; Steenbakkers, R. J. A. FlowInduced Crystallization. In Handbook of Polymer Crystallization; John Wiley \& Sons, Inc.: 2013; pp 399-432.

(2) Keller, A.; Kolnaar, H. W. H. Flow induced orientation and structure formation. In Materials Science and Technology: Processing of Polymers.; Meijer, H. E. H., Ed.; VCH: New York, 1997; Vol. 18.

(3) Janeschitz-Kriegl, H. Crystallization Modalities in Polymer Melt Processing: Fundamental Aspects of Structure Formation; Springer: New York, 2009.

(4) Schultz, J. M. Polymer Crystallization. The Development of Crystalline Order in Thermoplastic Polymers; Oxford University Press: Oxford, 2001.

(5) Seki, M.; Thurman, D. W.; Oberhauser, J. P.; Kornfield, J. A. Shear mediated crystallization of iPP: the role of long chain-long chain overlap. Macromolecules 2002, 35, 2583-2594.

(6) Jerschow, P.; Janeschitz-Kriegl, H. The role of long molecules and nucleating agents in shear-induced crystallization of isotactic polypropylenes. Int. Polym. Process. 1997, 12, 72-77.

(7) Balzano, L.; Kukalyekar, N.; Rastogi, S.; Peters, G. W. M.; Chadwick, J. C. Crystallization and dissolution of flow induced precursors. Phys. Rev. Lett. 2008, 100, 048302.

(8) Hsiao, B. S.; Yang, L.; Somani, R. H.; Avila-Orta, C. A.; Zhu, L. Unexpected shish-kebab structures in sheared polymer melts. Phys. Rev. Lett. 2005, 94, 117802.

(9) van Drongelen, M.; van Erp, T. B.; Peters, G. W. M. Quantification of non-isothermal, multi-phase crystallization of isotactic polypropylene: The influence of cooling rate and pressure. Polymer 2012, 53, 4758-4769.

(10) van Erp, T. B.; Roozemond, P. C.; Peters, G. W. M. Flowenhanced Crystallization Kinetics of iPP during Cooling at Elevated Pressure: Characterization, Validation, and Development. Macromol. Theory Simul. 2013, 22, 309-318.

(11) Roozemond, P. C.; van Drongelen, M.; Ma, Z.; Hulsen, M. A.; Peters, G. W. M. Modeling flow-induced crystallization in isotactic polypropylene at high shear rates. J. Rheol. 2015, 59, 613-642.

(12) Somani, R. H.; Yang, L.; Zhu, L.; Hsiao, B. S. Flow-induced shish-kebab precursor structures in entangled polymer melts. Polymer 2005, 46, 8587-8623.

(13) Mykhaylyk, O.; Chambon, P.; Graham, R. S.; Patrick, J.; Fairclough, A.; Olmsted, P. D.; Ryan, A. J. The Specific Work of Flow as a Criterion for Orientation in Polymer Crystallization. Macromolecules 2008, 41, 1901-1904.

(14) Pogodina, N. V.; Winter, H. H.; Srinivas, S. Strain effects on physical gelation of crystallizing isotactic polypropylene. J. Polym. Sci., Part B: Polym. Phys. 1999, 37, 3512-3519.

(15) Zhao, B.; Li, X.; Huang, Y.; Cong, Y.; Ma, Z.; Shao, C.; An, H.; Yan, T.; Li, L. Inducing Crystallization of Polymer through Stretched Network. Macromolecules 2009, 42, 1428-1432.

(16) Yan, T.; Zhao, B.; Cong, Y.; Fang, Y.; Cheng, S.; Li, L.; Pan, G.; Wang, G.; Li, X.; Bian, F. Critical Strain for Shish-Kebab Formation. Macromolecules 2010, 43, 602-605.

(17) Coccorullo, I.; Pantani, R.; Titomanlio, G. Spherulitic Nucleation and Growth Rates in an iPP under Continuous Shear Flow. Macromolecules 2008, 41, 9214-9223.

(18) Fernandez-Ballester, L.; Thurman, D. W.; Kornfield, J. A. Realtime depth sectioning: Isolating the effect of stress on structure development in pressure-driven flow. J. Rheol. 2009, 53, 1229-1254.
(19) Hadinata, C.; Boos, D.; Gabriel, C.; Wassner, E.; Rüllmann, M.; Kao, N.; Laun, M. Elongation-induced crystallization of a high molecular weight isotactic polybutene-1 melt compared to shearinduced crystallization. J. Rheol. 2007, 51, 195.

(20) Lee, K.-G.; Schultz, J. M. The development of structure and mechanical properties in poly(ethylene terephthalate) fibres during heat treatment under stress. Polymer 1993, 34, 4455-4470.

(21) Balzano, L.; Rastogi, S.; Peters, G. W. M. Crystallization and precursors during fast short term shear. Macromolecules 2009, 42, 2088-2092.

(22) Ma, Z.; Balzano, L.; Portale, G.; Peters, G. W. M. Flow induced crystallization in isotactic polypropylene during and after flow. Polymer 2014, 55, 6140-6151.

(23) Janeschitz-Kriegl, H. Conditions of nucleation in crystallizable polymers: Reconnaissance of positions - A critical evaluation. Colloid Polym. Sci. 1997, 275, 1121-1135.

(24) Azzurri, F.; Alfonso, G. C. Life time of shear induced nucleation precursors. Macromolecules 2005, 38, 1723-1728.

(25) Cavallo, D.; Azzurri, F.; Balzano, L.; Funari, S.; Alfonso, G. C. Flow Memory and Stability of Shear-Induced Nucleation Precursors in Isotactic Polypropylene. Macromolecules 2010, 43, 9394-9400.

(26) Azzurri, F.; Alfonso, G. C. Insights into Formation and Relaxation of Shear-Induced Nucleation Precursors in Isotactic Polystyrene. Macromolecules 2008, 41, 1377-1383.

(27) Hamad, F. G.; Colby, R. H.; Milner, S. T. Lifetime of FlowInduced Precursors in Isotactic Polypropylene. Macromolecules 2015, 48, 7286-7299.

(28) Balzano, L.; Rastogi, S.; Peters, G. W. M. Self-nucleation of polymers with flow: The case of bimodal polyethylene. Macromolecules 2011, 44, 2926-2933.

(29) Ma, Z.; Balzano, L.; Peters, G. W. M. Pressure Quench of FlowInduced Crystallization Precursors. Macromolecules 2012, 45, 42164224.

(30) Schultz, J. M.; Lin, J. S.; Hendricks, R. W.; Petermann, J.; Gohil, R. M. Annealing of Polypropylene Films Crystallized from a Highly Extended Melt. J. Polym. Sci., Polym. Phys. Ed. 1981, 19, 609-620.

(31) Petermann, J.; Gohil, R. M.; Schultz, J. M.; Hendricks, R. W.; Lin, J. S. The Kinetics of Defect Clustering in Fibrillar Poypropylene Crystals. J. Polym. Sci., Polym. Phys. Ed. 1982, 20, 523-534.

(32) Gupte, K. M.; Motz, H.; Schultz, J. M. Microsctructure Rearrangement during the Heat Treatment of Melt-Drawn Poly(Ethylene Terephtalate) Fibers. J. Polym. Sci., Polym. Phys. Ed. 1983, 21, 1927-1953.

(33) Grubb, D. T.; Keller, A. Thermal contraction and extension in fibrous crystals of polyethylene. Colloid Polym. Sci. 1978, 256, 218233.

(34) Grubb, D. T.; Hill, M. J. The core structure of shish-kebab crystals of polyethylene. J. Cryst. Growth 1980, 48, 321-333.

(35) Van der Beek, M. H. E.; Peters, G. W. M.; Meijer, H. E. H. Influence of shear flow on the specific volume and the crystalline morphology of isotactic polypropylene. Macromolecules 2006, 39, $1805-1814$

(36) Macosko, C. W. Rheology, Principles, Measurements and Application; Wiley-VCH: New York, 1994.

(37) Housmans, J. W.; Steenbakkers, R. J. A.; Roozemond, P. C.; Peters, G. W. M.; Meijer, H. E. H. Saturation of Pointlike Nuclei and the Transition to Oriented Structures in Flow-Induced Crystallization of Isotactic Polypropylene. Macromolecules 2009, 42, 5728-5740.

(38) Portale, G.; Cavallo, D.; Alfonso, G. C.; Hermida-Merino, D.; van Drongelen, M.; Balzano, L.; Peters, G. W. M.; Goossens, J. P. G.; Bras, W. Polymer crystallization studies under processing-relevant conditions at the SAXS/WAXS DUBBLE beamline at the ESRF. J. Appl. Crystallogr. 2013, 46, 1681-1689.

(39) http://www.esrf.eu/computing/scientific/FIT2D/.

(40) Housmans, J. W.; Balzano, L.; Santoro, D.; Peters, G. W. M.; Meijer, H. E. H. A design to study flow induced crystallization in a multipass rheometer. Int. Polym. Process. 2009, 24, 185-197. 
(41) van Meerveld, J.; Peters, G. W. M.; Hutter, M. Towards a rheological classification of flow induced crystallization experiments of polymer melts. Rheol. Acta 2004, 44, 119-134.

(42) Pantani, R.; Balzano, L.; Peters, G. W. M. Flow-Induced Morphology of iPP Solidified in a Shear Device. Macromol. Mater. Eng. 2012, 297, 60-67.

(43) Housmans, J. W.; Steenbakkers, R. J. A.; Roozemond, P. R.; Peters, G. W. M.; Meijer, H. E. H. Saturation of pointlike nuclei and the transition to oriented structures in flow induced crystallization of isotactic polypropylene. Macromolecules 2009, 42, 5728-5740.

(44) Keller, A.; Kolnaar, H. W. H. Flow-induced orientation and structure formation. In Processing of Polymers; Meijer, H., Ed.; WileyVCH: Weinheim, 1997; Vol. 18, pp 189-268.

(45) Roozemond, P. C.; Ma, Z.; Cui, K.; Li, L.; Peters, G. W. M. Multimorphological Crystallization of Shish-Kebab Structures in Isotactic Polypropylene: Quantitative Modeling of Parent-Daughter Crystallization Kinetics. Macromolecules 2014, 47, 5152-5162.

(46) Kumaraswamy, G.; Issaian, A. M.; Kornfield, J. A. Shearenhanced crystallization in isotactic polypropylene. 1. Correspondence between in situ-shear-optics and ex situ structure determination. Macromolecules 1999, 32, 7537-7547.

(47) Custodio, F. J. M. F.; Steenbakkers, R. J. A.; Anderson, P. D.; Peters, G. W. M.; Meijer, H. E. H. Model Development and Validation of Crystallization Behavior in Injection Molding Prototype Flows. Macromol. Theory Simul. 2009, 18, 469-494.

(48) Mykhaylyk, O. O.; Chambon, P.; Impradice, C.; Fairclough, J. P. A.; Terrill, N. J.; Ryan, A. J. Control of Structural Morphology in Shear-Induced Crystallization of Polymers. Macromolecules 2010, 43, 2389-2405.

(49) Hamad, F. G.; Colby, R. H.; Milner, S. T. Onset of FlowInduced Crystallization Kinetics of Highly Isotactic Polypropylene. Macromolecules 2015, 48, 3725-3738.

(50) Stribeck, N. X-ray Scattering of Soft Matter; Springer-Verlag: Berlin, 2007.

(51) Ma, Z.; Balzano, L.; Peters, G. W. M. Dissolution and Reemergence of Flow-Induced Shish in Polyethylene with a Broad Molecular Weight Distribution. Macromolecules 2016, 49, 2724-2730.

(52) Bastiaansen, C. W. M.; Lemstra, P. J. Melting behaviour of gelspun-drawn polyolefins, Makromol. Chem. Makromol. Chem., Macromol. Symp. 1989, 28, 73-84.

(53) Lieberwirth, I.; Loos, J.; Petermann, J.; Keller, A. Observation of shish crystal growth into nondeformed melts. J. Polym. Sci., Part B: Polym. Phys. 2000, 38, 1183-1187.

(54) Mykhaylyk, O. O.; Fernyhough, C. M.; Okura, M.; Fairclough, J. P. A.; Ryan, A. J.; Graham, R. Monodisperse macromolecules - A stepping stone to understanding industrial polymers. Eur. Polym. J. 2011, 47, 447-464.

(55) Avila-Orta, C.; Burger, C.; Somani, R.; Yang, L.; Marom, G.; Medellin-Rodriguez, F. J.; Hsiao, B. S. Shear-induced crystallization of isotactic polypropylene within the oriented scaffold of noncrystalline ultrahigh molecular weight polyethylene. Polymer 2005, 46, 88598871.

(56) Keum, J. K.; Burger, C.; Hsiao, B. S.; Somani, R.; Yang, L.; Chu, B.; Kolb, R.; Chen, H.; Lue, C. T. Synchrotron X-ray scattering studies of the nature of shear-induced shish-kebab structure in polyethylene melt. Prog. Colloid Polym. Sci. 2005, 130, 114-126.

(57) Förster, S.; Timmann, A.; Konrad, M.; Schellbach, C.; Meyer, A.; Funari, S.; Mulvaney, P.; Knott, R. Scattering Curves of Ordered Mesoscopic Materials. J. Phys. Chem. B 2005, 109, 1347-1360.

(58) Pedersen, J. S. Analysis of small-angle scattering data from colloids and polymer solutions: modeling and least-squares fitting. $A d v$. Colloid Interface Sci. 1997, 70, 171-210.

(59) Roozemond, P. C.; Steenbakkers, R. J. A.; Peters, G. W. M. A Model for Flow-enhanced Nucleation Based on Fibrillar Dormant Precursors. Macromol. Theory Simul. 2011, 20, 93-109.

(60) Roozemond, P. C.; van Drongelen, M.; Ma, Z.; Spoelstra, A. B.; Hermida-Merino, D.; Peters, G. W. M. Self-Regulation in FlowInduced Structure Formation of Polypropylene. Macromol. Rapid Commun. 2015, 36, 385-390.
(61) Avrami, M. Kinetics of phase change. I. General theory. J. Chem. Phys. 1939, 7, 1103-1112. 